\title{
Hemofiliya xəstəliyinin yayılma səviyyəsinin iqtisadi və inzibati rayonlarda xüsusiyyətlori
}

\author{
E.Qədimova ${ }^{1}$, M.M. Kazımova ${ }^{2}$ \\ ${ }^{1}$ Ә. Oliyev adına Azarbaycan Dövlat Həkimlarin Təkmillaşdirilmasi İnstitutunun Hematologiya kafedrası \\ ${ }^{2}$ Elmi-Praktiki Hemofiliya Markazi
}

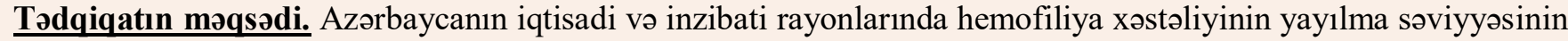
xüsusiyyətlərinin öyrənilməsi.

Tədqiqatın materialları vo metodları.Tədqiqatın təqdim olunan hissəsi Azərbaycanın 4 iqtisadi (Naxçıvan, Lənkəran, Şəki-Zaqatala, Quba-Xaçmaz) və 17 inzibati (Balakən, Zaqatala, Qax, Şəki, Oğuz, Qəbələ, Astara, Lənkəran, Lerik, Yardımlı, Masallı, Cəlilabad, Qusar, Xaçmaz, Quba, Şabran, Siyəzən) rayonunun məlumat bazasına əsaslanmışdır. İlkin məlumat kimi Respublika Klinik xəstəxanasının hemotoligiya şöbəsində və onun bazasında yerləşən Azərbaycan Dövlət Həkimləri Təkmilləşdirmə İnstitutunun hemotologiya kafedrasının hemofiliya registrinin məlumatları istifadə olunmuşdur.

$\mathrm{Bu}$ regionlar üzrə 2015-ci ilin sonunda qeydiyyatda olan xəstələr yaşa görə qruplaşdırılmış $(0-4,5-13,14-18,19$ $44,45+)$ və hər 100 min ayrı-ayrı yaş qrupunda olan əhaliyə düşən hemofiliya xəstəliyinin sayı müəyyın edilmişdir. Regionlarda əhalinin yaşı barədə məlumat Dövlət Statistika Komitəsinin rəsmi saytından götürülmüşdür.

Məlumatların statistik işlənməsi keyfiyyət əlamətlərinin təhlili metodları ilə Excel proqra-mının "məlumatların analizi” zərfinin köməyi ilə həyata keçirilmiş̧ir. Hemofiliyanın əhalinin yaşından asılı yayılma səviyyəsinin dinamikası ən kiçik kvadratlar metodu ilə qiymətləndirilmiş, əsas trendin yaxşı approksimasiyasını təmin edən reqressiya tənlikləri seçilmişdir.

Alınmıș nəticələr. Azərbaycanın Şəki-Zaqatala, Lənkəran, Quba-Xaçmaz və Naxçıvan iqtisadi rayonlarında hemofiliya xəstəliyinin ayrı-ayrı yaş qruplarında olan əhali arasında yayılması barədə məlumatlar 1-ci cədvəldə əks olunmuşdur.

Açar sözlor: hemofiliya, müalicə, tədqiqat.

Giris. Hemofiliya xəstəliyinin ayrı-ayrı ölkələrdə, ölkələrin regionlarında fərqli səviyyədə yayılması müşahidə olunur [1-3,5-8]. Rusiya Federasiyasında bu xəstəliyin yayılma səviyyəsi $(0,106 \%$ ) Böyük Britaniyanın müvafiq göstəricilərinə yaxın $(0,096 \%$ ) , Ukrayna və Belarusla müqayisədə $(0,058$ və $0,060 \%)$ xeyli yüksəkdir [1-3]. Belarusiyanın Brest, Vitebsk, Qomel, Qrodnensk, Minsk və Moqilyovsk vilayətlərində (müvafiq olaraq: 0,$0907 ; 0,0822 ; 0,0785 ; 0,1023 ; 0,0855$ və 0,0763\%o hemofiliya A və B-nin summar yayılma səviyyəsi də fərqlidir. Xəstəli-yin yayılması barədə məlumat müalicə profilkatika işlərinin prioritetinə təsir edir. Ona görə də Azərbaycanın regionlarında, xüsusən iqtisadi və inzibati rayonlarında hemofiliyanın yayılmasının öyrənilməsi aktual məsələdir.

İqtisadi rayonlar üzrə hemofiliyanın bütün əhali arasında yayılma səviyyəsinin nisbətən aşağ göstəricisi Lənkəranda $\quad(7,5 \pm 0,9 \%$ \%000; $95 \%$ etibarlılıq intervalı 5,7-9,3\%0000), yüksək göstəricisi isə Quba-Xaçmaz bölgəsində $(10,8 \pm 1,4 \%$ \%000; $95 \%$ etibarlılıq intervalı 8,0-13,6\% \% qeoo) qdə alınmışdır. $\mathrm{Bu}$ göstəricilər arasında fərq statistik dürüstdür $(p<0,05)$. Müqayisə olunan regionların hamısında hemofiliya xəstəliyinin yayılma səviyyəsi ölkənin müvafiq göstəricisindən $(17,2 \pm 0,4 \% 0000)$ statitik dürüst $(p<0,01)$ 1,6 dəfədən çox azdır. Beləliklə, hemofiliyanın nisbətən az yayıldığı regionlar arasında fərq mövcuddur.

İnzibati rayonlar üzrə hemofiliya xəstəliyinin yayılma səviyyəsinin nisbətən aşağı göstəricisi Qax rayonunda $(1,8 \% 0000)$, yüksək göstəricisi isə Siyəzən rayonunda $(22,2 \pm 7,4 \%$ \%000 $)$ qeydə alınmışdır $\quad(p<0,05)$. Şəki-Zaqatala, Lənkəran, Quba-Xaçmaz iqtisadi rayonlar üzrə göstəricinin orta səviyyəsi $9,06 \%$, onun standart xətas 1,32 , medianası isə $7,87 \%$ o000 təşkil edir. Onun 25,50 və 
75-ci sentillərinin həddi müvafiq olaraq 6,$3 ; 7,9$ və $11,7 \% 0000$ olmuşdur (cədvəl 2).

Hemofiliyanın yayılma səviyyəsinin sentil bölgüsünü əsas götürərək regionun rayonları 4 qrupa bölünə bilər:

0 - 25-ci sentillərə müvafiq rayonlar $(\leq 6,3 \%$ \% Balakən, Qax, Astara, Lənkəran, Qusar;

25 - 50-ci sentillərə müvafiq rayonlar $(6,4$ 79\% $\% 000)$ : Zaqatala, Oğuz, Qəbələ, Masall1, Colilabad;

50 - 75-ci sentillərə müvafiq rayonlar $(8,0$ 11,7\%0000): Lerik, Xaçmaz, Quba;

$75-100$-ci sentillərə müvafiq rayonlar $(\geq 11,8 \%$ o000): Şəki, Yardımlı, Şabran, Siyəzən.

Hemofiliyanın 0-4 yaşll uşaqlar arasında yayılma səviyyəsi Azərbaycan üzrə $8,7 \pm 1,0 \%$, Naxçıvan üzrə $6,3 \pm 3,6 \%$, Şəki-Zaqatala iqtisadi rayonu üzrə $5,9 \pm 3,4 \% 0000$, Lənkəran üzrə $5,6 \pm 2,5 \%$ Quba-Xaçmaz üzrə $1,9 \pm 1,9 \%$ \%000 təşkil edərək bir-birindən dürüst fərqlənir $(p<0.05)$. İnzibati rayonlar üzrə xəstəliyin 0-4 yaşlı uşaqlar arasında yayılma səviyyəsini

\begin{tabular}{|c|c|c|c|c|c|c|}
\hline $\begin{array}{l}\text { İqtisadi və inzibati } \\
\text { rayonlar }\end{array}$ & $0-4$ & $5-13$ & $14-18$ & $19-44$ & $45+$ & Com \\
\hline Balakən & - & $9,4 \pm 9,4$ & - & $2,5 \pm 2,5$ & $3,4 \pm 3,4$ & $3,2 \pm 1,8$ \\
\hline Zaqatala & $10,4 \pm 10,4$ & $6,4 \pm 6,4$ & $22,0 \pm 15,0$ & $7,8 \pm 3,9$ & $2,6 \pm 2,6$ & $7,2 \pm 2,4$ \\
\hline Qax & - & - & - & $4,6 \pm 4,6$ & - & $1,8 \pm 1,8$ \\
\hline Şəki & $12,5 \pm 8,8$ & $16,5 \pm 8,2$ & - & $15,3 \pm 4,6$ & $9,0 \pm 4,0$ & $12,7 \pm 2,7$ \\
\hline Oğuz & - & - & - & $6,0 \pm 6,0$ & $15,9 \pm 11,2$ & $7,0 \pm 4,0$ \\
\hline Qəbələ & - & $17,8 \pm 9,8$ & $11,2 \pm 11,2$ & $12,5 \pm 5,6$ & - & $7,9 \pm 2,8$ \\
\hline $\begin{array}{c}\text { Şəki-Zaqatala iqtisadi } \\
\text { rayonu }\end{array}$ & $5,9 \pm 3,4$ & $10,3 \pm 3,6$ & $6,4 \pm 3,7$ & $9,5 \pm 2,0$ & $4,9 \pm 1,6$ & $7,8 \pm 1,1$ \\
\hline Astara & - & $12,2 \pm 8,6$ & $12,3 \pm 12,3$ & $4,7 \pm 3,3$ & - & $4,82,1$ \\
\hline Lənkəran & $9,8 \pm 6,9$ & $6,6 \pm 4,6$ & $12,7 \pm 9,0$ & $7,6 \pm 2,9$ & $1,6 \pm 1,6$ & $6,3 \pm 1,7$ \\
\hline Lerik & $12,1 \pm 2,1$ & $7,7 \pm 7,7$ & $27,0 \pm 19,0$ & $8,7 \pm 5,0$ & - & $8,7 \pm 3,3$ \\
\hline Yardımlı & - & - & $14,9 \pm 14,9$ & $23,1 \pm 9,4$ & $22,9 \pm 13,2$ & $15,8 \pm 5,0$ \\
\hline Masallı & $9,3 \pm 6,5$ & - & $5,8 \pm 5,8$ & $7,9 \pm 3,0$ & $12,7 \pm 4,8$ & $7,9 \pm 1,9$ \\
\hline Colilabad & - & $16,3 \pm 7,3$ & $9,8 \pm 6,8$ & $2,3 \pm 1,6$ & $4,0 \pm 2.8$ & $6,7 \pm 1,8$ \\
\hline $\begin{array}{c}\text { Lənkəran iqtisadi } \\
\text { rayonu }\end{array}$ & $5,6 \pm 2,5$ & $7,4 \pm 2,3$ & $11,9 \pm 3,9$ & $7,3 \pm 1,4$ & $5,8 \pm 1,6$ & $7,5 \pm 0,9$ \\
\hline Qusar & - & - & - & $5,4 \pm 3,8$ & $3,6 \pm 3,6$ & $3,2 \pm 1,8$ \\
\hline Xaçmaz & - & $8,1 \pm 5,7$ & $7,4 \pm 7,4$ & $23,5 \pm 5,9$ & $2,0 \pm 2,0$ & $11,7 \pm 2,6$ \\
\hline Quba & $6,3 \pm 6,3$ & $16,4 \pm 8,2$ & $7,4 \pm 7,4$ & $12,4 \pm 4,4$ & $2,2 \pm 2,2$ & $9,2 \pm 2,4$ \\
\hline Şabran & - & - & - & $27,0 \pm 11,0$ & $26,0 \pm 13,0$ & $17,8 \pm 5,6$ \\
\hline Siyəzən & - & $15,4 \pm 15,4$ & - & $50,0 \pm 17,7$ & - & $22,2 \pm 7,4$ \\
\hline $\begin{array}{l}\text { Quba- Xaçmaz iqtisadi } \\
\text { rayonu }\end{array}$ & $1,9 \pm 1,9$ & $9,0 \pm 3,4$ & $4,8 \pm 3,4$ & $19,3 \pm 3,0$ & $4,8 \pm 1,8$ & $10,8 \pm 1,4$ \\
\hline Naxçıvan MR & $6,3 \pm 3,6$ & $8,0 \pm 3,6$ & $8,4 \pm 4,8$ & $5,0 \pm 1,7$ & $11,9 \pm 3,2$ & $7,7 \pm 1,3$ \\
\hline
\end{tabular}

statistik dürüst (göstəricilər kiçik olduğuna görə) qiymətləndirmək olmur.

0-4 yaşlı əhali ilə müqayisədə 5-13 yaşlı əhali arasında hemofiliyanın yayılma səviyyəsi həm ölkə üzrə, həm də müqayisə olunan iqtisadi rayonlar üzrə yüksəkdir, statistik dürüst artım yalnız ölkə üzrə təsdiq olunur $(8,7 \pm 1,0$ və $14,6 \pm 1,1 \% 0000 ; p<0,01)$. Hemofiliyanın yayılma səviyyəsinin artımı sonrakı yaş qrupunda yalnız ölkə üzrə və Lənkəran iqtisadi rayonu üzrə qeydə alınmışdır, Şəki-Zaqatala, Quba-Xaçmaz iqtisadi rayonlarında 14-18 yaş qrupunda hemofiliyanın yayılma səviyyəsi 5-13 yaş qrupu ilə müqayisədə azdır. Bütün hallarda artım və azalma statistik dürüst deyildir.

Codval № 1.

Azərbaycanin Şəki-Zaqatala, Lonkəran, QubaXaçmaz vo Naxçıvan iqtisadi rayonlarında hemofiliyanın yayılma səviyyəsi (müvafiq yaşlarda $100 \mathrm{~min}$ nafara) 


\section{Codval № 2.}

Şəki-Zaqatala, Lənkəran, Quba-Xaçmaz iqtisadi rayonlarina daxil olan inzibati rayonlarda hemofiliya xastaliyinin yayllma saviyyasinin tasviri statistikası

\begin{tabular}{|c|c|c|c|c|c|}
\hline $\begin{array}{c}\text { Statistik } \\
\text { göstəricilər }\end{array}$ & $\begin{array}{c}\text { Göstəricilər } \\
\text { in } \\
\text { səviyyəsi }\end{array}$ & $\begin{array}{c}\text { Sentil } \\
\text { ər }\end{array}$ & $\begin{array}{c}\text { Hemofiliy } \\
\text { anın } \\
\text { səviyyəsi } \\
\text { \% } \% 000\end{array}$ & $\begin{array}{c}\text { Sentil } \\
\text { lər }\end{array}$ & $\begin{array}{c}\text { Hemofiliy } \\
\text { anın } \\
\text { səviyyəsi } \\
\text { \% } 0000\end{array}$ \\
\hline Orta & 9,06 & 0 & 1,8 & 56,2 & 7,9 \\
\hline Standartxəta & 1,32 & 6,2 & 3,2 & 62,5 & 8,7 \\
\hline Mediana & 7,87 & 12,5 & 3,2 & 68,7 & 9,2 \\
\hline $\begin{array}{c}\text { Standartkənar } \\
\text { açıxma }\end{array}$ & 5,46 & 18,7 & 4,8 & 75,0 & 11,7 \\
\hline Dispersiya & 29,58 & 25,0 & 6,3 & 81,2 & 12,7 \\
\hline Ekses & 0,79 & 31,2 & 6,7 & 87,5 & 15,8 \\
\hline Asimmetriya & 1,03 & 37,5 & 7,0 & 93,7 & 17,7 \\
\hline Minimum & 1,8 & 43,7 & 7,2 & 100,0 & 22,2 \\
\hline Maksimum & 22,2 & 50,0 & 7,9 & & \\
\hline Say & 17 & & & & \\
\hline
\end{tabular}

Xəstəliyin yaş qruplarında yayılma səviyyəsinin statistik dürüst səciyyəsi 19-44 yaş intervalında müşahidə olunur və müvafiq olaraq təşkil edir: $9,5 \pm 2,0 \%$ etibarliliq intervalı 5,5 $13,5 \%$ Şəki-Zaqatala, $7,3 \pm 1,4 \% 0000(95 \%$ etibarlılıq intervalı 5,5-10,1\%0000) Lənkəran, $19,3 \pm 3,0 \% 0000(95 \%$ etibarliliq intervalı 13,3 -

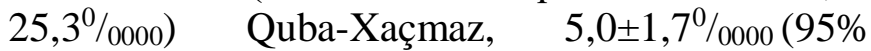
etibarlılıq intervalı 1,6-8,4\%000) Naxçıvan iqtisadi rayonlarında vo $21,3 \pm 0,8 \% 0000(95 \%$ etibarliliq intervalı 19,4-22,9\% $\% 000$ ) ölkə üzrə bütövlükdə. İqtisadi rayonlar arasında göstəricinin səviyyəsinə görə fərq statistik dürüstdür. Hemolifiyanın 19-44 yaşlı əhali arasında yayılma səviyyəsi Naxçıvanda nisbətən kiçik, Quba-Xaçmaz iqtisadi rayonunda isə xeyli yüksəkdir. $\mathrm{Bu}$ yaş qruunda hemofiliyanın
$16,9 \pm 1,6$ yayılma səviyyəsi inzibati rayonlar üzrə $2,3 \%$ (Conlilabad) ilə 27,0 $\pm 11,0 \% 0000$ (Şabran) arasında tərəddüd edir və bir-birindən statistik dürüst fərqlənir $(p<0,01)$.

Hemofiliyanın 45 və yuxarı yaşlı əhali arasında yayılma səviyyəsi Azərbaycanda $15,2 \pm 0,8 \% 0000(95 \%$ etibarliliq intervali 13,6 $16,8 \%$ \%000), Naxçıvanda $11,9 \pm 3,2 \% 0000(95 \%$ etibarlılıq intervalı 5,5-18,3\%0000), Quba-Xaçmaz iqtisadi rayonunda $4,8 \pm 1,8 \% 0000(95 \%$ etibarliliq intervali $0,8-8,4 \% 0000$ ), Lonkəran iqtisadi rayonunda $5,8 \pm 1,6 \%$ etibarliliq intervalı 2,6 $9,0 \% 0000)$, Şəki-Zaqatala iqtisadi rayonunda $4,9 \pm 1,6 \% 0000$ (95\% etibarliliq intervalı $1,7-8,1 \%$ \%o00) təşkil edərək bir-birindən statistik dürüst fərqlənir $(\mathrm{p}<0,01)$.

19-44 yaş intervlında hemofiliyanın yayılma səviyyəsinə görə iqtisadi rayonların ardıcıllığ (Quba-Xaçmaz, Şəki-Zaqatala, Lənkəran və Naxçıvan) 45 və yuxarı yaşlarda müvafiq göstəriciyə görə ardıcıllıqdan (Naxçıvan, Lənkəran, Şəki-Zaqatala və Quba-Xaçmaz) kəskin fərqlənir. Hemofiliya xəstəliyinin yaşdan asılı (x) əhali arasında yayılmasının (y) əsas trendi əyrixəttlidir və aşağıdakı tənliklərlə ifadə olunur $\left(\mathrm{R}^{2}=1\right)$ :

Quba-Xaçmaz iqtisadi rayonu üzrə: $\mathrm{y}=-$ $3,2375 x^{4}+37,375 x^{3}-148,96 x^{2}+240,92 x-124,2$;

Lənkəran iqtisadi rayonu üzrə: $\mathrm{y}=1 \mathrm{x}^{4}$ $11,967 x^{3}+48,15 x^{2}-73,883 x+42,3$;

Şəki-Zaqatala iqtisadi rayonu üzrə: $y=0,25 \mathrm{x}^{4}$ $4,45 x^{3}+25,3 x^{2}-53,1 x+37,9$

Naxçıvan iqtisadi rayonu üzrə: $y=0,675 x^{4}$ $7,15 \mathrm{x}^{3}+25,375 \mathrm{x}^{2}-34,5+21,9$

Alınmıs nəticələrin müzakirəsi. Azərbaycanın Şəki-Zaqatala, Lənkəran, Quba-Xaçmaz və Naxçıvan iqtisadi rayonlaqrında əhali arasında hemofiliya xəstəliyinin yayılması (müvafiq olaraq: $7,8 \pm 1,1 ; 7,5 \pm 0,9 ; 10,8 \pm 1,4$ və $7,7 \pm 1,3 \% 0000)$ ölkə üzrə ümumi səviyyədən $(17,2 \pm 0,4 \% 0000)$ statistik dürüst azdır və Belarusiyanın [1] regionları səviyyəsinə $(7,6-10,2 \%$ \%000) yaxındır. $\mathrm{Bu}$ iqtisadi rayonlar Azərbaycanda hemofiliya xəstəliyinin nisbətən az yayıldığ 1 rayonlarına aiddirlər. Amma iqtisadi rayonlardan fərqli olaraq inzibati rayonlar arasında hemofiloya xəstəliyinin yayılmasının səviyyəsi daha geniş intervalda $\left(1,8-22,2^{0} / 0000\right)$ 
dəyişir.

İnzibati rayonlar arasında Şəki, Yardımlı, Şabran və Siyəzən rayonları hemofiliyanın yayılması səviyyəsinə görə $(\geq 11,8 \% 0000)$ seçilir və bu rayonlarda göstəricinin səviyyəsi ümumi respublika səviyyəsinə yaxındır. Hemofiliyanın ən az müşahidə olunduğu rayonlara Balakən, Qax, Astara, Lənkəran və Qusar aiddir $(\leq 6,3 \% 0000)$.

Hemofiliya əhalinin ayrı-ayrı yaş qruplarında forqli səviyyədə qeydə alınır. Xəstəliyin yaş dinamikasının ümumi trendi aydın nəzərə çarpmır, onu ifadə edən polinominal reqressiya tənlikləri regionlar üzrə fərqli səciyyələrə malikdir.

\section{Naticalor}

1.Hemofiliya xəstəliyinin nisbətən az yayıldığ Şəki-Zaqatala $\quad(7,8 \pm 1,1 \%$ \%000), Lonkəran (7,5 $\pm 0,9 \%$ \%000), Quba-Xaçmaz $(10,8 \pm 1,4 \% 0000)$ və Naxçıvan $(7,7 \pm 1,3 \%$ iqtisadi rayonları bir-birindən xəstəliyin yayılma səviyyəsinə görə dürüst fərqlənirlər $\quad(p<0,05)$. 2.Inzibati rayonlar arasinda hemofiliya xəstəliyinin yayılmasına görə fərq daha böyükdür $\left(1,8 \% 0000^{-d ə n} \quad 22,2 \%\right.$ \%000-ə qədər $)$, xəstəliyin riski Şəki, Yardıml,, Şabran və Siyəzən rayonlarında $(\geq 11,8 \%$ o000) əhəmiyyətli dərəcədə yüksəkdir. 3.İnzibati və iqtisadi rayonlar çərçivəsində hemofiliya xəstəliyinin yayılma səviyyəsinin əhalinin yaş qruplarında fərqi statistik dürüstdür, yaş dinamikası əyri xətlidir və yaxşı aproksimasiyanı təmin edən $\left(\mathrm{R}^{2}=1,0\right)$ tənliklərlə ifado olunur.

Maliyyə Mənbəyi: Məqalənin hazırlanmasında heç bir kənar maliyyə mənbəyindən istifadə edilməyib.

Maraqların toqquşması: Qeyd edilməyib.

\section{ӘDӘВIYYAT:}

1.Дашкевич Э.В., Ольковик Ю.В., Рудб М.С. и др. Анализ распростра-ненности гемофилии в республике Беларусь // Медицинские новости, 2014, №9, с. 29-30

2.Кудрявцева Л.М., Плющ О.П., Копылов К.Г. и др. Характеристики алгоритмов гемостатической терапии гемофобии // Проблема гематологии и переливание крови. 2006, №2, c. 41-46

3.Полянская Т.Ю. Современные представления о патогенезе, профилактике и лечении гемофобии, осложненной развитием ингибитора // Гематология и трансфузиология, 2002 №3, с.38-42.

4.Стентон $\quad$ Г. Медико-биологическая статистика. Москва. Практика. 1999. 459 с.

5.Canadian Hemophilia Registry. http://www.fhs.memaster./ca/chr/ Accessed February, 2014

6.Sackson S.C., Yang M., Minuk Z. et al. Prophylaxis in order Canadian adults with hemophilia A: lessons and more questions// BMC Hematology, 2015, 15:4

7.Petkova R., Chakarov S. and Kremensky I. Genetic analysis of hemophilia A in Bulgaria // BMC Blood Disorders, 2004 4:2

8.Zozulya N.J., Phyushch O.P., Kopylov K.G., Severova T.V. Russian register of patients with inhibitor hemophilia // XXVIII International Congress of the World Federation of Hemophilia 2006,12,2:07 p. 212 